\title{
Clinical Study with Rapid Serological Detection of Rotavirus Infection in Diarrheic Neonatal Calves
}

\author{
Ahmed Abdel-Rady*, Ahmed MA Zaitoun and Zainab MA Youssef \\ Infectious Diseases, Department of Animal Medicine, Faculty of Veterinary \\ Medicine, Assiut University, Egypt \\ *Corresponding Author: Ahmed Abdel-Rady, Infectious Diseases, Department of \\ Animal Medicine, Faculty of Veterinary Medicine, Assiut University, Egypt.
}

Received: December 27, 2021

Published: January 28, 2022

(C) All rights are reserved by Ahmed

Abdel-Rady., et al.

\begin{abstract}
Rotavirus is an enteritis causing pathogen in neonatal calves. A total number of 175 neonatal enteric calves were clinically examined. Their feces were sampled to rapidly serotested for Rotavirus detection. The clinical findings on Rotavirus diarrheic calves were anorexia, weakness, arched back with straining during defecation, variable degree of dehydration. Feces were pasty yellowish with and/or without flakes of clotted blood. Body temperature, respiratory and heart rates were varying. The collected fecal samples were serotested by Latex agglutination test (LAT) and Immunochromatographic assay (ICA). Results of LAT and ICA indicated that the positive samples of Rotavirus infection were $9.68 \%$ and $8.54 \%$, respectively. It is concluded that Rotavirus infection plays an outstanding role in enteritis of neonatal calves of Assiut Governorate and control measures should be attained. LAT and ICA are effortlessly field serotests in screening of Rotavirus infection in diarrheic neonatal calves.
\end{abstract}

Keywords: Rotavirus; Calf Diarrhea; LAT; ICA

\section{Abbreviations}

LAT: Latex Agglutination Test; ICA: Immunochromatographic Assay

\section{Introduction}

Enteritis in newborn calves is an outstanding problem with an economic dimension to cattle herds [1]. Enormous pathogens were incriminated as an etiologic agent of neonatal calves' enteritis. Rotavirus occupied the second grad of calves' enteropathogens following Escherichia coli causing intestinal villous atrophy ensuing malabsorption and maldigestion of the infected cases [2-4]. Diagnosis of enteritis due to Rotavirus infection based on clinical signs is currently unachievable. The neonatal enteric cases must subject to laboratory tests. Laboratory detection of Rotavirus infection depends on identification of viral antigen in fecal samples [5]. Latex agglutination test (LAT) and Immunochromatographic assay (ICA) are commercially available rapid methods for Rota viral detection. Currently, neonatal calves' enteritis associated with Escherichia coli were documented. Contrariwise, data on Rotavirus infection in diarrheic calves in Assiut Governorate appears to be scanty [2]. Consequently, the current work performed to carry-out a rapid sero-screening of neonatal enteric calves associated with Rotavirus infection coming The Veterinary Teaching Hospital (VTH) of Assiut University, Assiut, Egypt.

\section{Material and Method}

\section{Animal and clinical examination}

During the period of investigation, Jan. 2018 to Nov. 2019, a total of 175 enteric neonatal calves aged from 3 to 60 days were clinically examined at VTH and bloodsera of the examined cases were tested serologically. Clinical examination of the enteric calves was carried out based on [6]. 
Sampling

The fecal samples of the enteric cases were subsequently collected in sterile plastic cups and stored for serological testing.

\section{Serological testing}

\section{Serodetection of Rotavirus antigen by LAT}

Ninety-three fecal samples were subjected to LAT for detection of Rotavirus antigen by a commercial kit (REF-M80 Rotascreen ${ }^{\circledR}$ kit Microgen Bioproducts limited, United Kingdom). Latex particles in Rotascreen ${ }^{\circledR}$ Test reagent is coated with rabbit antibodies raised against a pool of different Rotavirus isolates. When a fecal extract is mixed with test reagent any Rotavirus antigens present will react with sensitizing antibodies, resulting in visible agglutination of latex particles. A Control Reagent, latex particles coated with normal rabbit globulin, was included to identify non-specific reactions which may occur with some fecal specimens. The test was carried out based on the manufacturer's guidelines.

Serological detection of Rotavirus antigen by ICA (Rotascreen ${ }^{\circledR}$ dipstick strip/fastest strip and Rotavirus rapid test device)

Eighty-two fecal samples were subjected to ICA for detection of Rotavirus antigen by a commercial kit (Rotascreen ${ }^{\circledR}$ Dipstick M580, Microgen Bioproducts limited, United Kingdom and Atlas Medical, United Kingdom). This test is a qualitative ICA for detection of Rotavirus antigen in fecal samples. The membrane is pre-coated with mouse monoclonal antibodies, on the test band region, against viral antigens. During testing, the sample is allowed to react with the colored conjugate (Anti-Rotavirus mouse monoclonal antibodiesred microspheres) which was pre-dried on the test. The mixture then moves upward on membrane by capillary action. As the sample flows through test membrane, colored particles migrate. In the case of positive result, specific antibodies present on membrane capture colored conjugate, producing red band. The mixture continues to move across membrane to immobilized antibody placed in control band region, colored band always appears. The test was done based on the manufacturer's instructions.

\section{Results}

\section{Clinical findings}

Clinical findings of the examined enteric calves revealed signs of severe enteritis with variable degree of diarrhea. The most cases came to VTH are dehydrated. Thriftiness, weakness and recumbences of the enteric cases were also noticed. The examined calves were emaciated. Straining with arched back and raised tail was obvious (Figure 1a). The eyes were sunken in most cases $(65 / 83)$ Range of body temperature respiratory of the enteric cases was 37.6 to $39.8{ }^{\circ} \mathrm{C}$. The fecal consistency of the enteric calves was varying from pasty to profuse watery. Eight (50\%), 4 (25\%) and $4(25 \%)$ were suffering from profuse watery diarrhea, pasty to watery diarrhea and pasty diarrhea, respectively. Eleven (68.75\%) cases had yellowish semi-pasty diarrhea (Figure 1b). Four (25\%) cases with greenish diarrhea and one case had yellowish brown diarrhea. Odor of fecal samples was varying from unpleasant to offensive. Seven (43.75\%) cases had unpleasant odor diarrhea and $9(56.25 \%)$ cases have offensive diarrhea. Fourteen $(87.50 \%)$ and one (6.25\%) fecal sample contained mucus and mucus with clotted blood, respectively.
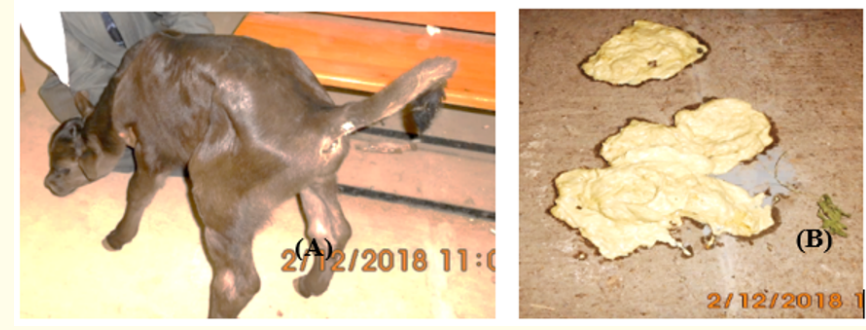

Figure 1: A: Enteric emaciated calf with straining, arched back and lateral deviation of tail during evacuation of intestinal contents, B: Pale yellowish pasty diarrhea of the same calf.

\section{Serological diagnosis}

Serological diagnosis of Rotavirus antigen by using LAT

Nine $(9.68 \%)$ of the tested fecal samples of the enteric calves were serologically positive (Figure 2 and Table 1 ).

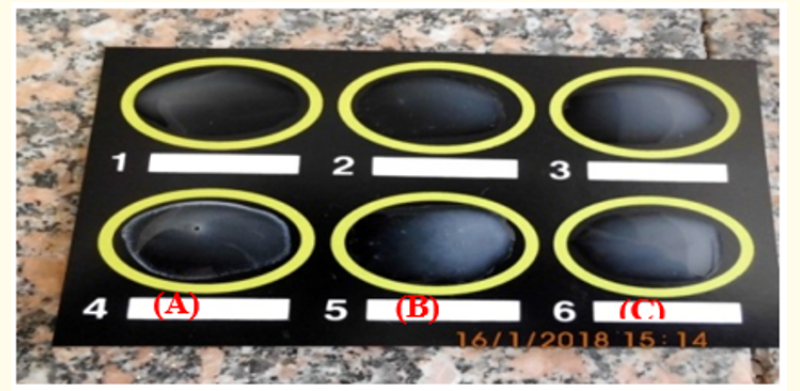

Figure 2: LAT for detection of Rotavirus antigen. $(\mathrm{A} 1,4)$ Positive result (agglutination or sandy like). $(\mathrm{B} 2,5)$ and $(\mathrm{C} 3,6)$ Negative results (milky suspension). 


\begin{tabular}{|l|c|c|c|}
\hline Serological test & No. & Positive & \% \\
\hline LAT & 93 & 9 & 9.68 \\
\hline ICA & 82 & 7 & 8.54 \\
\hline
\end{tabular}

Table 1: Serological detection of Rotavirus in the examined enteric calves by LAT and ICA $(n=175)$.

\section{Serological detection of Rotavirus antigen by ICA}

Seven $(8.54 \%)$ of the serotested fecal samples of diarrheic calves were positive (Figure 3,4)

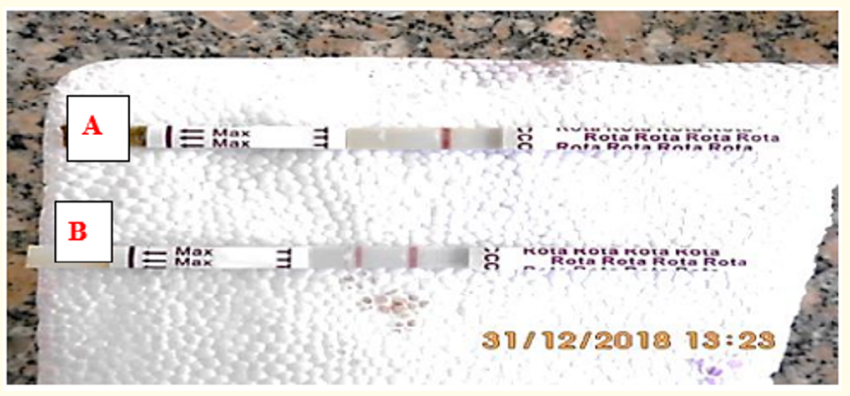

Figure 3: Rotascreen ${ }^{\circledR}$ Dipstick strip/FASTest strip for detection of Rotavirus antigen. A: Negative result (One pink line in the Control region). B: Positive result (pink line in the Test region in addition to the Control line).

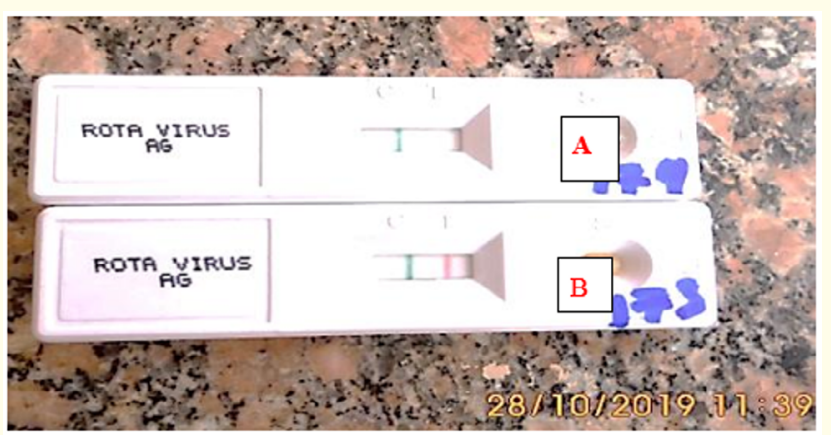

Figure 4: Rapid Test device for detection of Rotavirus antigen. A: Negative result (only one green band (Control line) appears in the white central zone of the test (Control region). B: Positive result (In addition of green band (Control line), a distinguishable red band (Result line) appears in the white central zone of the test (Result region).

\section{Discussion}

Neonatal enteritis is a multifactorial problem due to interaction between immune status of calves, environment, management, nutrition beside enteropathogenes. The later plays an important role in neonatal enteritis particularly in herds with sublevel hygienic measures. Rotavirus is frequently implicated as a one of the major pathogens of neonatal calf diarrhea $[1,7]$. The current work indicated that Rotavirus infection was serologically detected in $16(9.14 \%)$ cases of the investigated enteric calves $(n=175)$ with characteristic clinical features of enteritis with variable degree of diarrhea. Mostly the enteric discharge of diseased calves was yellowish watery feces contained mucus, followed by anorexia, emaciation, dehydration and weakness. Some enteric calves had straining with or without arched back. The systemic reactions of the seropositive cases were varied from case to another; however, tachycardia and polypnea were prominent. Similar findings were reported by $[2,8]$. Detailed pathophysiological changes of the intestinal tracts associated with Rotavirus infection are described by [9]. The triple protein coat of the Rotavirus helps them to escape unaffected from acidic $\mathrm{pH}$ of stomach and digestive enzymes in the gut. VP7 and VP4 of outer layer of capsid of Rotavirus bind to host cell through sialic acid receptor. After contact with cellular receptor, VP4 spikes undergo conformational change through cleavage to VP5 and VP8 by protease enzyme (trypsin). Furthermore, Rotavirus invades the surface epithelial cells of the small intestinal villi inducing stunts and exfoliates enterocytes' villi of small intestine which become covered by immature cells arising from the villous crypt. This immature cell causing disorder in intestinal mucosal barriers in association with spectacular reduction in absorption capacity and in secretion of digestive enzymes that lead to profuse viscous fluid containing undigested and unabsorbed nutrients in intestinal lumen. The nonstructural protein, NSP4 acts as a viral enterotoxin has both secretory and subsequent anti-secretory actions which result in loss of $\mathrm{Cl}^{-}$into intestinal lumen that increasing of microbial activity and osmotic imbalance causing draw more water into gut lumen. Subsequently diarrhea, weakness, dehydration, acidosis and hypoglycemia lead to respiration and heart work could be changed, depression and all physiological function may be alterated $[9,10]$.

Serologically, LAT and ICA are feasible rapid tests for detection of Rotavirus in feces of animals [1,11]. The current work suggests that LAT and ICA are possible methods for examining fecal samples 
collected from calves with suspected diarrhea that may infected by Rotavirus. The present study indicated that $9.68 \%$ of fecal samples of enteric calves were positive by LAT. $[12,13]$ elucidated that the percentage of Rotavirus infection in the enteric calves was $9.59 \%$ and $6.76 \%$, respectively. conversely, highest percentage of infection with Rotavirus of the enteric calves were reported by [14-16]. Their results indicated that the percentage of infection with Rotavirus was $32.08 \%, 35.25 \%$, and $65 \%$, respectively.

The current study revealed that 7 (8.54\%) of 82 diarrheic fecal samples of calves were positive by ICA; These 7 enteric cases were as follow 4 (12.12\%) of 33 by Rotascreen ${ }^{\circledR}$ Dipstick strip/ FAST strip and 3 (6.12\%) of 49 by Rotavirus Rapid Test device. The obtained result of FAST strip was higher than result obtained by [8] who indicated that the percentage of positive serological detection of Rotavirus of tested enteric calves was $10 \%$. On contrary, highest rate of Rotavirus infection in enteric calves were concluded by $[15,17]$. They indicated that percentage of Rotavirus seropositive enteric cases was $35.25 \%$, and 53.6\%, respectively. Contrariwise, $[10,18,19]$ indicated that rate of Rotavirus infection in enteric calves was $36 \%, 15.63 \%$ and $12.50 \%$, respectively. Such variations in rate of infection of Rotavirus in enteric calves may be attributed to geographical variation, difference in timing of samples collection, clinical phase of the disease is a suitable time for sampling to obtain the optimum result from a test, hygienic measures and environmental conditions.

\section{Conclusion}

Rotavirus plays an outstanding role in enteritis of neonatal calves. LAT and ICA are a reliable and rapid method for the detection of Rotavirus infection in neonatal diarrheic calves. Attention should be directed toward viruses in any control programs put to overcome enteritis in neonatal calves in Assiut Governorate.

\section{Acknowledgements}

Not applicable.

\section{Ethics Approval and Consent to Participate}

Not applicable.

\section{Competing Interests}

The authors declare that they have no competing interests.
Funding

Not applicable.

Bibliography

1. Barua SR., et al. "Comparison of diagnostic tests for detection of bovine Rotavirus A in calf feces". Macedonian Veterinary Review 44.1 (2021): 1-9.

2. Zaitoun AMA., et al. "Enteric Rota and Corona viruses' infection in neonatal calves". Assiut Veterinary Medical Journal 64.156 (2018): 8-17.

3. El-Sadek FE., et al. "Investigation of Rota and Corona viruses as causative agents for diarrhea in Egyptian calves". Suez Canal Veterinary Medical Journal 24.2 (2019): 257-272.

4. Singh S., et al. "Epidemiological study of naturally occurring bovine Rotavirus infection in organized dairy farms, India". Biological Rhythm Research (2019): 1-9.

5. Mayameei A., et al. "Evaluation of relationship between Rotavirus and Coronavirus infections with calf diarrhea by capture ELISA". Comparative Clinical Pathology Journal 19 (2010): 553557.

6. Jackson PGG and Cockcroft PD. "Clinical examination of farm animals”. 1st Ed. USA. (2002): 95-101.

7. Sawant PM., et al. "Molecular characterization of unusual G10P [33], G6P [14] genomic constellations and evidence of zooanthroponosis in bovines". Infection, Genetics and Evolution (2020): 1-27.

8. Barua SR. "Clinico-pathology and Molecular characterization of bovine Rotavirus infection in calves in south-eastern part of Bangladesh, PhD". Thesis, Faculty of Veterinary Medicine, Chittagong Veterinary and Animal Sciences University, Bangladesh (2019).

9. Brown CC., et al. The Alimentary tract. "In Jubb, Kennedy and Palmer's of Domestic Animals". Edited by Grant Maxie. 5th Edition. Vol. II, chapter 1. Sunders LTD. (2007): 69-130.

10. Hassan MN. "G and P typing and sequence analysis of group A Rotavirus in calves and lambs in Kashmir", PhD. Thesis, Faculty of Post-Graduate Studies Sher-e-Kashmir, University of Agricultural Sciences and Technology of Kashmir, India (2014).

11. Makwana PM., et al. "Detection of bovine Rotavirus (BRV) infection in neonatal calves of in and around Navsari district of South Gujarat, India". Journal of Entomology and Zoology Studies 8.2 (2020): 1092-1097. 
12. Okada N and Matsumoto $\mathrm{Y}$. "Bovine Rotavirus G and P types and sequence analysis of the VP7 gene of two G8 bovine Rotaviruses from Japan". Veterinary Microbiology 84 (2002): 297305.

13. Dulgheroff ACB., et al. "Analysis of bovine Rotavirus strains circulating in diarrheic dairy calves in Uberaba", Minas Gerais, Brazil, during 2008-2009". Arquivo Brasileiro de Medicina Veterináriae Zootecnia (Brazilian Journal of Veterinary and Animal Science 68.4 (2016): 1090-1094.

14. Singh TC and Jhala MK. "Comparing Relative Sensitivity and Specificity of LA and RNA-PAGE in Detecting Bovine Rotaviruses". Buffalo Bulletin 30.1 (2011a): 36-44.

15. Izzo MM., et al. "Comparisons of three diagnostic techniques for detection of Rotavirus and Coronavirus in calf faeces in Australia". Australian Veterinary Journal 90.4 (2012): 122-129.

16. Muhammid HA., et al. "Estimating the sensitivity and Specificity of Reverse transcriptase polymerase chain reaction (RT-PCR) with Rota virus latex agglutination test (Virogen Rotatest) in calves suffering from diarrhea in Karbala province". Scientific Journal of Medical Research 1.4 (2017): 110-114.

17. Abdulazeez AA and Abed MN. "Genotyping of Rotavirus in Neonatal Calves with Acute Gastroenteritis in Iraq". Advances in Microbiology 7 (2017): 863-870.

18. Sakli GU., et al. "Investigation of bovine Coronavirus and bovine Rotavirus by rapid diagnosis kit and RT-PCR in diarrheic calf feces". Journal of Istanbul Veterinary Sciences 3.3 (2019): 57-63.

19. Babalola MO. "Group A Rotavirus genotypes among calf herds in Southwest Nigeria and implications for human Rotavirus vaccines' efficiency". Open Journal of Veterinary Medicine 10 (2020): 1-13.

\section{Assets from publication with us}

- Prompt Acknowledgement after receiving the article

- Thorough Double blinded peer review

- Rapid Publication

- Issue of Publication Certificate

- High visibility of your Published work

Website: www.actascientific.com/

Submit Article: www.actascientific.com/submission.php

Email us: editor@actascientific.com

Contact us: +919182824667 